OPEN ACCESS

Edited by:

Mauro Lo Rito,

IRCCS Policlinico San Donato, Italy

Reviewed by:

Elumalai Appachi,

Baylor College of Medicine,

United States

Biagio Castaldi,

Università degli Studi di Padova, Italy

*Correspondence:

Tran Minh Dien

dientm@nch.org.vn

tThese authors have contributed equally to this work and share first

authorship

Specialty section:

This article was submitted to

Pediatric Cardiology,

a section of the journal

Frontiers in Cardiovascular Medicine

Received: 14 July 2021 Accepted: 02 November 2021

Published: 29 November 2021

Citation:

Tuan TA, Xoay TD, Phuc PH,

Hung DV, Dung NT, Truong NLT,

Thuan NV and Dien TM (2021)

Pediatric Acute Myocarditis With Short-Term Outcomes and Factors for

Extracorporeal Membrane Oxygenation: A Single-Center Retrospective Cohort Study in

Vietnam.

Front. Cardiovasc. Med. 8:741260.

doi: 10.3389/fcvm.2021.741260

\section{Pediatric Acute Myocarditis With Short-Term Outcomes and Factors for Extracorporeal Membrane Oxygenation: A Single-Center Retrospective Cohort Study in Vietnam}

\author{
Ta Anh Tuan 1,2,3t, Tran Dang Xoay ${ }^{1 \dagger}$, Phan Huu Phuc ${ }^{1}$, Dau Viet Hung ${ }^{1,2}$, \\ Nguyen Trong Dung ${ }^{1}$, Nguyen Ly Thinh Truong ${ }^{4}$, Nguyen Van Thuan ${ }^{5}$ and \\ Tran Minh Dien ${ }^{2,5 *+}$
}

\begin{abstract}
${ }^{1}$ Pediatric Intensive Care Unit, Vietnam National Children's Hospital, Hanoi, Vietnam, ${ }^{2}$ Children's Department, University of Medicine and Pharmacy, Vietnam National University, Hanoi, Vietnam, ${ }^{3}$ Department of Pediatric, Hanoi Medical University, Hanoi, Vietnam, ${ }^{4}$ Department of Cardiovascular Surgery, Children Heart Center, Vietnam National Children's Hospital, Hanoi, Vietnam, ${ }^{5}$ Surgical Intensive Care Unit, Vietnam National Children's Hospital, Hanoi, Vietnam
\end{abstract}

Objective: Data on the management and outcomes of acute myocarditis treated with extracorporeal membrane oxygenation (ECMO) among low- and middle-income countries are limited. This study aimed to determine the short-term outcomes and also identify factors associated with ECMO use among children with acute myocarditis at a tertiary children's hospital in Vietnam.

Methods: A single-center, retrospective observational study was conducted between January 2016 and February 2021. Pediatric patients with acute myocarditis, aged 1 month to 16 years, were included.

Results: In total, 54 patients (male, 46\%; median age, 7 years) with acute myocarditis were included; 37 of them received ECMO support. Thirty percent (16/54) of the patients died, and 12 of them received ECMO. Laboratory variables that differed between survivors and non-survivors included median left ventricular ejection fraction (LVEF) at $48 \mathrm{~h}$ (42 vs. $25 \% ; p=0.001$ ), platelet count (304 g/L [interquartile range (IQR): 243-271] vs. $219 \mathrm{~g} / \mathrm{L}$ [IQR: 167-297]; $p=0.014)$, and protein (60 g/dl [IQR: 54-69] vs. 55 [IQR: 50-58]; $p=0.025)$. Among patients who received ECMO, compared with the survivors, non-survivors had a low LVEF at $48 \mathrm{~h}$ (odds ratio (OR), 0.8; 95\% confidence interval $(\mathrm{Cl}): 0.6-0.9 ; p=0.006)$ and high vasoactive-inotropic score (OR, 1.0; 95\% Cl: 1.0-1.0; $p=0.038)$ and lactate (OR, 2.8; 95\% Cl, 1.2-6.1; $p=0.013)$ at $24 \mathrm{~h}$ post-ECMO.

Conclusions: The case fatality rate among children with acute myocarditis was 30 and $32 \%$ among patients requiring ECMO support. Arrhythmia was an indicator for ECMO in patients with cardiogenic shock.

Keywords: acute myocarditis, cardiac arrhythmia, extracorporeal membrane oxygenation, mortality, pediatrics 


\section{INTRODUCTION}

Acute myocarditis in children is a rare but life-threatening disease that can cause sudden death (1). Early diagnosis and prompt intervention play a pivotal role in the management of the disease. Current treatment is mainly supportive (2). Acute myocarditis may progress very quickly and eventually lead to cardiogenic shock requiring resuscitation and administration of intravenous inotropic agents $(1,2)$. Extracorporeal membrane oxygenation (ECMO) therapy is indicated for patients who are non-responsive to medical therapy and have an increased serum lactate concentration and evidence of organ failure (3). ECMO is an effective treatment modality in managing critical cases, with reported success rates of $50-83 \%(4,5)$. Factors associated with mortality include arrhythmia (3), dialysis (6), and endorgan hypoperfusion.

There are numerous studies on the deployment of ECMO for acute myocarditis in children in developed countries. Data on the management and outcomes of acute myocarditis treated with extracorporeal membrane oxygenation (ECMO) among low- and middle-income countries are limited.

This study aimed to determine short-term outcomes and identify factors associated with ECMO use among children with acute myocarditis at a tertiary children's hospital in Vietnam.

\section{MATERIALS AND METHODS}

\section{Patients and Case Definitions}

A single-center, retrospective observational study was conducted between January 2016 and February 2021 in the pediatric intensive care unit (PICU) of Vietnam National Children's Hospital. Informed consent was obtained from parents/guardians. The study was approved by the Ethics Council of Vietnam National Children's Hospital (approval number: 331-BVNTW-VNVSKTE).

Consecutive pediatric patients aged 1 month to 16 years who met the criteria for acute myocarditis were included (Figure 1). The definition and diagnostic criteria for acute myocarditis were adapted from Sagar et al. (7). Acute myocarditis was diagnosed for a patient who had clinical features of possible myocardial injury with cardiovascular symptoms and at least one of the following findings: (i) elevated biomarkers of cardiac injury, (ii) electrocardiogram (ECG) findings suggestive of cardiac injury, and (iii) abnormal cardiac function on echocardiogram in the absence of endomyocardial biopsy. Notably, magnetic resonance imaging (MRI) was not widely used to evaluate the cardiac function at our center.

Demographic, clinical, and laboratory data were collected as part of routine care. Demographic and clinical variables included age, sex, weight, presence of cough, runny nose, anorexia, abdominal pain, vomiting, chest pain, syncope, seizure, palpitation, fever, pallor, hypotension, gallop rhythm, heart murmur, edema, hepatomegaly, pulmonary edema, and time from the onset of symptoms to PICU admission. Laboratory variables included creatine kinase-MB (CK-MB), troponin I, N-terminal pro B type natriuretic peptide (NTproBNP), the total white blood cell (WBC) neutrophil, lymphocyte and platelet counts (PLT), C-reactive protein

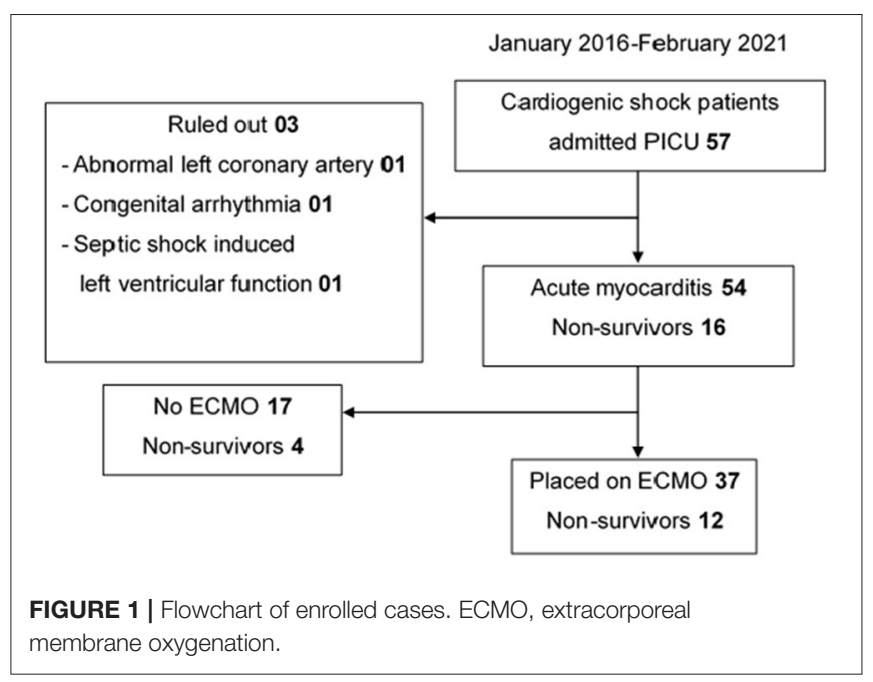

(CRP), serum urea, creatinine, alanine aminotransferase (ALT), aspartate aminotransferase (AST), albumin, and protein levels. Cardiac data obtained before and after ECMO included left ventricular ejection fraction (LVEF), left ventricular dilation, left ventricular diastolic diameter, abnormal segmental wall motion, pericardial effusion, pleural effusion, abdominal effusion, and ECG findings. Real-time polymerase chain reaction (RTPCR) was used to evaluate the presence of viral antigens in serum and respiratory tract aspirates. Adjunct therapies included defibrillation, pacemaker, hemodialysis, intravenous immunoglobulin (IVIG), and amiodarone. We did not use immunosuppressive medications for patients in this cohort.

\section{Extracorporeal Membrane Oxygenation}

Indications for ECMO therapy were according to the Extracorporeal Life Support Organization (8). The patients who qualified for ECMO had at least one of the following: (i) an oxygen index $>40$ for a total duration of $4 \mathrm{~h}$, (ii) cardiogenic shock with arrhythmia requiring supportive inotropes, (iii) cardiogenic shock without arrhythmia requiring supportive inotropes (vasoactive-inotropic score [VIS] $>40$ ), and (iv) lactic acidosis that did not improve with vasoactive-inotropic agents and pharmacologic therapies. For patients with a bodyweight of $\leq 20 \mathrm{~kg}$, we used the Maquet machine with the Rotaflow pump module (Maquet Cardiopulmonary, Rastatt, Germany) and an oxygenator; a Maquet PLS-i oxygenator (Maquet Cardiopulmonary, Rastatt, Germany) was only used for patients with a bodyweight of $\geq 20 \mathrm{~kg}$. Bio-Medicus cannulas (Medtronic, MN, USA) were used, and cannula size was selected according to the patient's body weight. We collected the following variables regarding ECMO therapy: ECMO mode, ECMO duration, time (in hours) from PICU admission to ECMO initiation, cannula sites (neck or groin), and the flow at 4 and $24 \mathrm{~h}$ on ECMO. Prior to and during ECMO therapy, clinical and laboratory variables, including heart rate and blood pressure, cardiac arrest, VIS, arterial blood gas and mixed venous oxygen saturation $\left(\mathrm{ScvO}_{2}\right)$, and blood lactate level, were collected. After the initiation of ECMO, hemorrhage, cannula deviation, clots 
in the oxygenator, hemolysis, and infection were considered complications of ECMO.

Criteria for the termination of ECMO were as follows: (i) recovery from shock, (ii) stable hemodynamics and overall condition upon decrease of ECMO to $30 \%$ of its maximum flow, (iii) normal chest X-ray, (iv) $\mathrm{pH}$ within the range of 7.357.45 , and (v) echocardiogram-confirmed recovery of ventricular function. We initially decreased the blood flow of the ECMO support to zero for $5 \mathrm{~min}$ and discontinued afterwards if the patient remained stable.

The VIS was calculated as follows: dopamine dose $(\mu \mathrm{g} / \mathrm{kg} / \mathrm{min})+$ dobutamine dose $(\mu \mathrm{g} / \mathrm{kg} / \mathrm{min})+100 \times$ epinephrine dose $(\mu \mathrm{g} / \mathrm{kg} / \mathrm{min})+10 \times$ milrinone dose $(\mu \mathrm{g} / \mathrm{kg} / \mathrm{min})+10,000 \times$ vasopressin dose (unit $/ \mathrm{kg} / \mathrm{min})+$ $100 \times$ norepinephrine dose $(\mu \mathrm{g} / \mathrm{kg} / \mathrm{min})(9)$.

Short-term outcomes, including survival and death from all causes, were assessed at discharge from the PICU.

\section{Statistical Analysis}

Continuous variables are expressed as the median and interquartile range (IQR), while categorical variables are expressed as a percentage. Comparisons between groups were evaluated using logistic regression analysis. Non-survival, a secondary outcome, is expressed as the odds ratio (OR) with corresponding 95\% confidence intervals (CIs). Multivariable logistic regression analysis was not performed due to the small sample size. The significance level was set at a two-sided $p<0.05$. IBM SPSS Statistics Software Version 20 (IBM Corp., Armonk, NY, USA) was used for statistical analyses.

\section{RESULTS}

\section{Patients}

In total, 54 patients (male, 46\%), median age of 7 years (IQR, 310), with acute myocarditis were included. The median weight was $18.5 \mathrm{~kg}$ (IQR, 10-29). The median length of PICU stay was 14 days (IQR, 12-19; range, 2-61 days).

\section{Signs and Symptoms}

The median time from the onset of symptoms to PICU admission was 3 days (IQR, 2-4). Signs and symptoms included cough (35\%), runny nose (18\%), anorexia (53\%), abdominal pain (33\%),

TABLE 1 | Comparison between survivors and non-survivors in terms of demographics, symptoms, and signs at the pediatric intensive care unit admission.

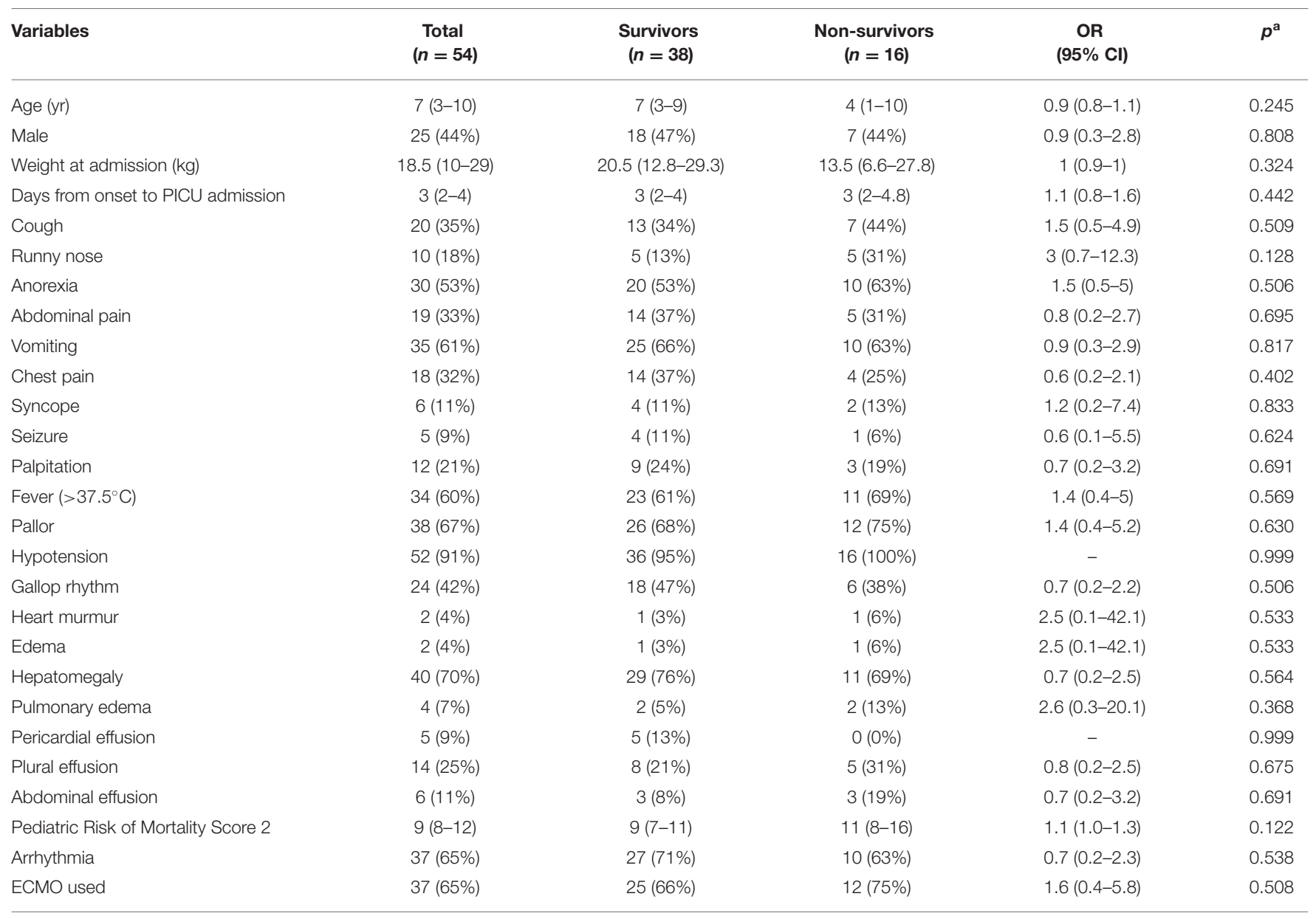

ECMO, Extracorporeal Membrane Oxygenation; OR, odds ratio, $\mathrm{Cl}$, confidence interval. ${ }^{a} \mathrm{p}<0.05$ was considered significant. The data are presented as the number (\%) or median (interquartile). Comparison between groups was analyzed by logistic regression analysis and expressed as OR with corresponding $95 \% \mathrm{Cl}$. 
TABLE 2 | Comparison between survivors and non-survivors in terms of laboratory data at admission, organ dysfunction, and treatments during the pediatric intensive care unit stay.

\begin{tabular}{|c|c|c|c|c|c|}
\hline Variables & $\begin{array}{l}\text { Total } \\
(n=54)\end{array}$ & $\begin{array}{c}\text { Survivors } \\
(n=38)\end{array}$ & $\begin{array}{l}\text { Non-survivors } \\
\quad(n=16)\end{array}$ & $\begin{array}{c}\text { OR } \\
(95 \% \mathrm{Cl})\end{array}$ & $p^{a}$ \\
\hline Creatin kinase-MB (U/L) & $91(44-173)$ & $91(45-150)$ & $78(26-251)$ & $1.0(1.0-1.0)$ & 0.834 \\
\hline Troponin I (ng/mL) & $20.7(3.8-132.7)$ & $20.7(3.8-96.7)$ & $22.2(1.4-298.3)$ & $1.0(1.0-1.0)$ & 0.271 \\
\hline $\begin{array}{l}\text { N-terminal pro B type natriuretic peptide } \\
\text { (pmol/L) }\end{array}$ & $3,090(1,625-5,930)$ & $3,090(1,286-4,934)$ & $3,593(1,759-7,950)$ & $1.0(1.0-1.0)$ & 0.360 \\
\hline White blood cell $\left(\times 10^{9} / \mathrm{L}\right)$ & $14(10.6-20)$ & $13.6(10.3-19.6)$ & $14.7(11.6-20.7)$ & $1.0(0.9-1.1)$ & 0.204 \\
\hline Neutrophil $\left(\times 10^{9} / \mathrm{L}\right)$ & $8.7(5.7-16)$ & $8.7(5.7-14.2)$ & $8.6(5.8-17.6)$ & $1.0(0.9-1.1)$ & 0.232 \\
\hline Lymphocyte (x 109/L) & $2.7(1.8-5)$ & $2.7(1.7-4.7)$ & $3.5(2.2-5.5)$ & $1.1(0.9-1.2)$ & 0.202 \\
\hline Platelet (× 109/L) & $280(214-356)$ & $304(243-371)$ & $219(167-297)$ & $0.9(0.9-0.9)$ & 0.014 \\
\hline C-reactive protein (mg/L) & $8.8(1.8-22.4)$ & $10.8(1.8-24.4)$ & $7.9(1.8-9.9)$ & $1.0(0.9-1.0)$ & 0.544 \\
\hline Urea (mmol/L) & $7.9(6.4-10.2)$ & $8(6-12)$ & $8(7-10)$ & $0.9(0.8-1.0)$ & 0.528 \\
\hline Creatinine $(\mu \mathrm{mol} / \mathrm{L})$ & $69(56-81)$ & $68(55-78)$ & $76(63-83)$ & $1.0(1.0-1.0)$ & 0.599 \\
\hline Alanine aminotransferase (IU/L) & $61(27-162)$ & $43(25-96)$ & $119(60-543)$ & $1.0(1.0-1.0)$ & 0.326 \\
\hline Aspartate transaminase (IU/L) & $172(99-469)$ & $141(81-457)$ & $376(134-1134)$ & $1.0(1.0-1.0)$ & 0.259 \\
\hline Albumin (g/L) & $36(33-39)$ & $36(34-39)$ & $35(32-39)$ & $0.9(0.8-1.1)$ & 0.330 \\
\hline Protein (g/L) & $57(53-67)$ & $60(54-69)$ & $55(50-58)$ & $0.9(0.8-1.0)$ & 0.025 \\
\hline Left ventricular ejection fraction (\%) & $35(26-42)$ & $40(30-46)$ & $31(24-38)$ & $1.0(0.9-1.0)$ & 0.148 \\
\hline Left ventricular diastolic diameter (mm) & $40(36-44)$ & $40(36.5-43)$ & $39.8(35.8-49.5)$ & $1.0(1.0-1.1)$ & 0.307 \\
\hline Left ventricular ejection fraction post $48 \mathrm{~h}(\%)$ & $37(29-46)$ & $42(31.5-49.5)$ & $25(20-30)$ & $0.8(0.7-0.9)$ & 0.001 \\
\hline Troponin I post 48h (ng/mL) & $2.7(0.7-11.5)$ & $2.3(0.7-7.5)$ & $6.6(0.4-36.9)$ & $1.0(1.0-1.0)$ & 0.690 \\
\hline $\begin{array}{l}\text { N-terminal pro B type natriuretic peptide post } \\
48 \mathrm{~h}(\mathrm{pmol} / \mathrm{L})\end{array}$ & $2,776(1,650-3,886)$ & $2,776(13.4-3,832)$ & $2,584(1,701-8,011)$ & $1.0(1.0-1.0)$ & 0.121 \\
\hline Creatinine highest $(\mu \mathrm{mol} / \mathrm{L})$ & $77(64-115)$ & 74 (59-95) & $86(69-160)$ & $1.0(1.0-1.0)$ & 0.883 \\
\hline Alanine aminotransferase highest (IU/L) & $211(84-842)$ & $124(67-574)$ & $436(150-1625)$ & $1.0(1.0-1.0)$ & 0.302 \\
\hline Aspartate transaminase highest (IU/L) & $508(143-1,715)$ & $271(114-1,046)$ & $1,275(591-4,476)$ & $1.0(1.0-1.0)$ & 0.082 \\
\hline Defibrillation & 17 (30\%) & $10(26 \%)$ & 7 (44\%) & $2.2(0.6-7.4)$ & 0.212 \\
\hline Pacemaker during the PICU stay & $10(18 \%)$ & $10(26 \%)$ & $0(0 \%)$ & - & 0.999 \\
\hline Continuous renal replacement therapy & $20(35 \%)$ & $12(32 \%)$ & $8(50 \%)$ & $2.2(0.7-7.2)$ & 0.205 \\
\hline Intravenous Immunoglobulin with & $13(23 \%)$ & $8(21 \%)$ & $5(31 \%)$ & $1.7(0.5-6.3)$ & 0.426 \\
\hline vasoactive-inotropic score at admission & $20(13.7-35)$ & $17.5(10.6-31.2)$ & $27.5(21.2-87.5)$ & $1.1(0.9-1.2)$ & 0.332 \\
\hline Amiodarone & $13(23 \%)$ & $10(26 \%)$ & $3(19 \%)$ & $0.6(0.2-2.8)$ & 0.554 \\
\hline Mechanical ventilation days & $10(7-13)$ & $10(7-12)$ & $10(4-16)$ & $1.0(0.9-1.1)$ & 0.949 \\
\hline PICU stay (d) & $14(12-19)$ & $14(13-20)$ & $11(4-19)$ & $0.9(0.9-1.0)$ & 0.134 \\
\hline
\end{tabular}

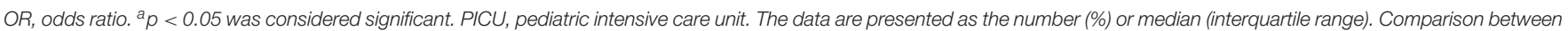
groups was analyzed by logistic regression analysis and expressed as OR with corresponding $95 \% \mathrm{Cl}$. The p-values were less than 0.05 .

vomiting (61\%), chest pain (32\%), syncope (11\%), seizure (9\%), palpitation $(21 \%)$, and fever $(60 \%)$. Signs of myocarditis on the day of PICU admission were pallor (67\%), hypotension (91\%), gallop rhythm (42\%), heart murmur (4\%), edema (4\%), hepatomegaly (70\%), and pulmonary edema (7\%). The median pediatric risk of mortality score was 9 (Table 1).

\section{Laboratory Data and Clinical Course}

Laboratory variables collected within $24 \mathrm{~h}$ of PICU admission, organ dysfunction, and therapies are shown in Table 2. Laboratory variables that differed significantly between survivors and non-survivors included LVEF at $48 \mathrm{~h}$ (42 vs. $25 \%$; $p=$ $0.001)$. PLT count and serum protein levels of non-survivors were significantly lower than that of survivors $(p=0.014$ and 0.025 , respectively). There were no significant differences between survivors and non-survivors for other laboratory variables.

Overall, 37 patients presented with ECG abnormalities on admission to the PICU. There were six patients with complete atrioventricular (AV) block, two with first degree AV block, one with second degree AV block, one with ventricular fibrillation, 15 with ventricular tachycardia, two with ST-elevation, two with right branch block, two with low voltage QRS, and six with premature ventricular contractions.

\section{Etiology of Acute Myocarditis}

Nine patients had positive microbiological diagnoses; five were infected with enteroviruses, one with combined enterovirus and adenovirus, one with adenovirus, one with bocavirus, and one with Staphylococcus aureus. 
TABLE 3 | Comparison of factors between patients with and without extracorporeal membrane oxygenation.

\begin{tabular}{|c|c|c|c|c|}
\hline Variables & $\begin{array}{l}\text { ECMO } \\
(n=37)\end{array}$ & $\begin{array}{c}\text { Non-ECMO } \\
(n=17)\end{array}$ & $\begin{array}{c}\text { OR } \\
(95 \% \mathrm{Cl})\end{array}$ & $p^{a}$ \\
\hline Age (yr) & $7(5.5-10)$ & $2(1-9)$ & $1.2(1.0-1.4)$ & 0.019 \\
\hline Male & $19(51 \%)$ & $6(35 \%)$ & $1.9(0.6-6.3)$ & 0.275 \\
\hline Dead & $12(32 \%)$ & $4(24 \%)$ & $1.6(0.4-5.8)$ & 0.508 \\
\hline Weight on admission PICU (kg) & $22(15.5-30)$ & $10(7-24.8)$ & $1.1(1.0-1.1)$ & 0.025 \\
\hline Days from onset to PICU admission & $3(2-4)$ & $3(2-4)$ & $1.1(0.8-1.5)$ & 0.773 \\
\hline Vasoactive-Inotropic Score at $24 \mathrm{~h}$ & $35(20-120)$ & $20(15-45)$ & $1.0(1.0-1.0)$ & 0.053 \\
\hline Arrhythmia & 33 (89\%) & $4(24 \%)$ & $26.8(5.8-123.5)$ & $<0.001$ \\
\hline Creatin kinase-MB (U/L) & $104(72-233)$ & $65(34-111)$ & $1.0(1.0-1.0)$ & 0.081 \\
\hline Troponin I (ng/mL) & $49.1(6.4-412.9)$ & $4.9(1.2-8.3)$ & $1.0(1.0-1.0)$ & 0.143 \\
\hline $\begin{array}{l}\text { N-terminal pro B type natriuretic } \\
\text { peptide }(\mathrm{pmol} / \mathrm{mL})\end{array}$ & $2,624(1,290-4,138)$ & $4,771(3,078-7,397)$ & $1.0(1.0-1.0)$ & 0.289 \\
\hline Left ventricular ejection fraction (\%) & $33(25.5-43)$ & 39 (30.5-42.5) & $1.0(0.9-1.0)$ & 0.748 \\
\hline Creatinine ( $\mu \mathrm{mol} / \mathrm{L})$ & $70(62-83)$ & $56(43-79)$ & $1.0(1.0-1.1)$ & 0.089 \\
\hline Alanine aminotransferase (IU/L) & $78(31-490)$ & $48(21-100)$ & $1.0(1.0-1.0)$ & 0.230 \\
\hline Aspartate transaminase (IU/L) & $285(109-1,081)$ & $138(66-227)$ & $1.0(1.0-1.0)$ & 0.118 \\
\hline $\begin{array}{l}\text { Continuous Renal Replacement } \\
\text { Therapy }\end{array}$ & $13(35 \%)$ & 7 (41\%) & $0.8(0.2-2.5)$ & 0.670 \\
\hline
\end{tabular}

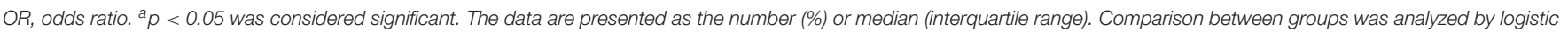
regression analysis and expressed as OR with corresponding $95 \% \mathrm{Cl}$. The $p$-values were less than 0.05 .

\section{Comparison Between Patients With and Without Extracorporeal Membrane Oxygenation}

In total, 37 patients received veno-arterial-ECMO therapy. The mortality rate of cases was $32 \%(12 / 37)$. Table 3 shows the characteristics between the ECMO group and the non-ECMO group. The presence of arrhythmia was significantly higher among patients receiving ECMO therapy (OR, 26.8; 95\% CI: 5.8$123.5 ; p<0.001)$. There were differences between the two groups for age and body weight ( $p=0.019$ and 0.025 , respectively).

The severity and hemodynamic characteristics of children receiving ECMO therapy are shown in Table 4. The variables that differed between non-survivors and survivors were LVEF at $48 \mathrm{~h}$ (OR, $0.8 ; 95 \%$ CI: $0.6-0.9 ; p=0.006$ ), VIS at $24 \mathrm{~h}$ post- ECMO therapy (OR, 1.0; 95\% CI: $1.0-1.0 ; p=0.038)$, and lactate level at $48 \mathrm{~h}$ post-ECMO therapy (OR, $2.8 ; 95 \% \mathrm{CI}: 1.2-6.1 ; p=0.013$ ).

Nine (24\%) patients experienced complications associated with ECMO therapy. Three patients had oxygenator clotting and required the oxygenator to be exchanged. One patient developed a swollen leg associated with the groin cannula. One patient experienced a hemorrhage at the cannula site, while another developed a pleural hemorrhage that caused the compression of the left ventricle. A patient with ventricular thrombosis, created by a swirling current in the heart chambers, died after decannulation due to failure of cardiac function. Two patients exhibited brain death.

\section{Adjunct Therapies}

Adjunct therapies included mechanical ventilation, inotropes, continuous venovenous hemofiltration, sedation, defibrillation, pacemaker, IVIG, cordarone, and ECMO. All the patients required invasive mechanical ventilation support and the administration of inotropes and vasopressors, such as dopamine, dobutamine, epinephrine, norepinephrine, and milrinone.

\section{Overall Outcomes}

Sixteen patients $(30 \%)$ died after discharge from the PICU. Among patients requiring ECMO, 25 patients survived (68\%). The median length of PICU stay for survivors in the ECMO and non-ECMO groups was 15 (IQR, 13-20) and 13 (IQR, 8-15) days, respectively.

Six patients (16\%) had a systemic infection during their ECMO treatment and PICU stay. Cultured samples were obtained from the blood and endotracheal tube. The organisms found were Acinetobacter baumannii in four patients, Pseudomonas aeruginosa in one, and Moraxella catarrhalis in one.

\section{DISCUSSION}

This study described ECMO application and short-term outcomes for 54 children with acute myocarditis in a single center from a low- and middle-income country. Overall, the case fatality rate was $30 \%$. Among patients receiving ECMO, the case fatality rate was $32 \%$, which was similar to the findings from previous studies conducted in high-income countries and Asia $(3,5,10,11)$. To the best of our knowledge, our case series is the first study with the highest case number so far conducted in a low- and middle-income country.

Similar to previous reports, gastrointestinal symptoms, such as anorexia, abdominal pain, and vomiting, were common $(12,13)$. All patients had cardiac-specific signs, such as pallor 
TABLE 4 | Comparison between survivors and non-survivors in terms of laboratory values before and $24 \mathrm{~h}$ after extracorporeal membrane oxygenation.

\begin{tabular}{|c|c|c|c|c|c|}
\hline ECMO parameters & $\begin{array}{l}\text { Total } \\
(n=37)\end{array}$ & $\begin{array}{c}\text { Survivors } \\
(n=25)\end{array}$ & $\begin{array}{l}\text { Non-survivors } \\
(n=12)\end{array}$ & $\begin{array}{c}\text { OR } \\
(95 \% \mathrm{Cl})\end{array}$ & $p$ \\
\hline Cardiac arrest before ECMO & $10(27 \%)$ & $5(20 \%)$ & $5(42 \%)$ & $2.9(0.6-12.9)$ & 0.173 \\
\hline Time from admission to ECMO (hr) & $6(3-12)$ & $6(3.5-14.5)$ & $5(3-11)$ & $1.0(0.9-1.0)$ & 0.508 \\
\hline ECMO duration (d) & $7(5-11.5)$ & $7(6-9.5)$ & $10(3-17)$ & $1.1(1.0-1.2)$ & 0.208 \\
\hline Cannula site (neck) & 30 (81\%) & $21(84 \%)$ & $9(75 \%)$ & $0.6(0.1-3.1)$ & 0.516 \\
\hline Cannula site (groin) & 7 (19\%) & $4(16 \%)$ & $3(25 \%)$ & $1.8(0.3-9.5)$ & 0.516 \\
\hline Flow at $4 \mathrm{~h}(\mathrm{ml} / \mathrm{kg} / \mathrm{min})$ & $87(69-101)$ & $87(71-100)$ & $88(62-122)$ & $1.0(1.0-1.0)$ & 0.250 \\
\hline Flow at $24 \mathrm{~h}$ (ml/kg/min) & $88(70-106)$ & 79 (70-98) & $96(74-122)$ & $1.0(1.0-1.0)$ & 0.243 \\
\hline Heart rate pre-ECMO (beats/min) & $150(133-167)$ & $150(121-165)$ & $153(141-184)$ & $1.0(1.0-1.0)$ & 0.546 \\
\hline Systolic blood pressure pre-ECMO (mmHg) & $92(74-100)$ & $92(74-108)$ & $88(72-97)$ & $1.0(0.9-1.0)$ & 0.187 \\
\hline Diastolic blood pressure pre-ECMO (mmHg) & $51(42-60)$ & $51(42-60)$ & $49(34-65)$ & $1.0(1.0-1.0)$ & 0.687 \\
\hline Vaso-Inotropic Score pre-ECMO & $55(35-121.3)$ & $47.5(35-113.8)$ & $70(20-137.5)$ & $1.0(1.0-1.0)$ & 0.493 \\
\hline Left ventricular ejection fraction (\%) & $33(25.5-43)$ & $40(28-49)$ & $30(23.5-35.9)$ & $1.0(0.9-1.0)$ & 0.246 \\
\hline Left ventricular ejection fraction post $48 \mathrm{~h}(\%)$ & $38(29-46)$ & $44(35-48.4)$ & $25(20-30)$ & $0.8(0.6-0.9)$ & 0.006 \\
\hline pH pre-ECMO & $7.35(7.26-7.41)$ & $7.35(7.29-7.41)$ & $7.35(7.18-7.42)$ & $0.1(0.0-22)$ & 0.331 \\
\hline $\mathrm{HCO}_{3}^{-}$pre-ECMO (mmol/L) & $18.2(13.9-22.2)$ & $17.6(14.2-21.6)$ & $19(12.7-24.3)$ & $1.0(0.9-1.2)$ & 0.615 \\
\hline Lactate pre-ECMO (mmol/L) & $3.6(2-5.8)$ & $3.6(1.8-6.5)$ & $3.8(2.3-5.5)$ & $1.0(0.8-1.2)$ & 0.922 \\
\hline Alanine aminotransferase pre-ECMO (IU/L) & $78(31-388)$ & $49(29-146)$ & $149(72-603)$ & $1.0(1.0-1.0)$ & 0.949 \\
\hline Aspartate transaminase pre-ECMO (IU/L) & $303(103-997)$ & $149(97-480)$ & $523(163-1200)$ & $1.0(1.0-1.0)$ & 0.909 \\
\hline $\begin{array}{l}\text { Mixed venous oxygen saturation }\left(\mathrm{SvO}_{2}\right) \\
\text { pre-ECMO (\%) }\end{array}$ & $58(45-66.5)$ & $58(44.5-66.5)$ & $60(47-66.8)$ & $1.0(1.0-1.1)$ & 0.615 \\
\hline $\begin{array}{l}\text { Mixed venous oxygen saturation }\left(\mathrm{SvO}_{2}\right) \\
\text { post-ECMO } 24 \mathrm{~h}(\%)\end{array}$ & $67(65-69.5)$ & $67(65-70)$ & $65(63-67.8)$ & $0.8(0.6-1.0)$ & 0.078 \\
\hline Oxygen index pre-ECMO & $3(2-5)$ & $3(2.5-5)$ & $3.5(2-5)$ & $0.9(0.7-1.2)$ & 0.525 \\
\hline Vaso-inotropic Score post-ECMO $24 \mathrm{~h}$ & $30(12.8-118.8)$ & $15(10-63.8)$ & $95(28.1-147.5)$ & $1.0(1.0-1.0)$ & 0.038 \\
\hline pH post-ECMO & $7.35(7.30-7.40)$ & $7.36(7.31-7.40$ & $7.35(7.27-7.43)$ & $0.2(0.0-229.6)$ & 0.656 \\
\hline $\mathrm{HCO}_{3}^{-}$post-ECMO (mmol/L) & $23.2(20.1-27.1)$ & $23(20.1-26.9)$ & $23.4(19.8-27.2)$ & $1.0(0.8-1.1)$ & 0.819 \\
\hline Lactate post-ECMO 48h (mmol/L) & $1.3(0.8-2.3)$ & $1.1(0.7-1.5)$ & $2.1(1.3-4.1)$ & $2.8(1.2-6.1)$ & 0.013 \\
\hline
\end{tabular}

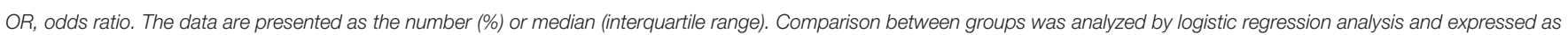
OR with corresponding $95 \% \mathrm{Cl}$. Statistical significance is set at $p<0.05$. The $p$-values were less than 0.05 .

and hypotension, upon admission to the PICU. Other cardiacspecific signs included gallop rhythm and hepatomegaly, which occurred in the majority of cases. Overall, four patients had pulmonary edema and hepatomegaly at admission to PICU; of these, one had cardiac arrest, and two demised. Fluid resuscitation, with $5 \mathrm{ml} / \mathrm{kg}$, was conservatively administered if needed; additionally, we promptly administered vasoactiveinotropic agents and established ECMO in the patients. After they were placed on ECMO, the symptom of pulmonary edema resolved. When pulmonary edema was persistent during ECMO, left ventricular compression was resolved using inotropic agents, including dopamine, dobutamine, and milrinone to increase contractility. If aortic valve opening and clinical improvement was not seen, an atrial septal defect creation should be considered $(14,15)$. We did not histologically confirm acute myocarditis in the children because of the lack of endocardial biopsy in the PICU. Hence, the diagnosis of acute myocarditis was based on the diagnostic criteria of Sagar et al. (7). Other differential diagnoses considered were heart failure secondary to primary arrhythmia, and anomalous left coronary artery from the pulmonary artery.
Similar to previous studies $(1,16,17)$, our results show that non-survivors had significantly lower LVEF on admission to the PICU than survivors and did not recover despite receiving ECMO support. Other abnormalities on echocardiography, also described in a previous study (18), included segmental wall motion and pericardial effusion. An echocardiogram is a commonly used valuable tool for evaluating left ventricular structure and function. In addition, ultrasound detection could also aid in the diagnosis of pleural and abdominal effusion.

Most patients in this study had arrhythmias that caused cardiac failure and resulted in an increased risk of sudden death, which was why ECMO was indicated. Rajagopal et al. (4) found that the presence of cardiac arrhythmias requiring therapy while on ECMO support was associated with an $\sim 3$-fold increase in mortality.

In this study, non-survivors had greater odds of VIS and serum lactate level at $24 \mathrm{~h}$ post-ECMO, which were signs of progressive organ failure. Together with irreversible cardiac dysfunction, they lead to multi-organ failure, this was the main cause of death in this study population. In another study, Duncan et al. (3) showed that elevated markers 
of end-organ function, such as creatinine, liver enzymes, and serum lactate, prior to and immediately after ECMO support were predictive of increased mortality. According to near-infrared spectroscopy, which obtained a continuous measurement of cerebral saturation (19), two patients experienced brain death.

Due to the inconclusive evidence of IVIG efficacy, we did not routinely administer IVIG for patients with myocarditis $(20,21)$. We only used IVIG according to the protocol in two cases with enterovirus infections, whereas empirical treatment was adopted for the remaining cases with high dose $2 \mathrm{~g} / \mathrm{kg} /$ $24 \mathrm{~h}$. There was no statistically significant difference between the survivors and non-survivors who were treated with IVIG. We did not use immunosuppressive medications such as corticoids for patients in this cohort. The strongest evidence for immunosuppressive therapy occurs in cardiac sarcoidosis, giant-cell myocarditis, and autoimmune rheumatic disease (2224). However, recent studies in adults and pediatrics reported that immunosuppressive therapy with IVIG and/or high dose methylprednisolone was associated with rapid LVEF recovery, short duration of ECMO support, and low mortality rate in fulminant myocarditis $(25,26)$. Nevertheless, further welldesigned studies are required to investigate this issue in the pediatric population.

The primary limitation of this study was the retrospective, single-center cohort and the small sample size. Consequently, the differences between the groups were not statistically significant. Another limitation of this study was the lack of follow-up on dilated cardiomyopathy.

\section{CONCLUSION}

Overall, the case fatality rate of children with acute myocarditis at a single PICU was 30 and $32 \%$ among patients requiring ECMO therapy. Non-survivors had lower odds of LVEF at $48 \mathrm{~h}$ and lower

\section{REFERENCES}

1. Foerster SR, Canter CE, Cinar A, Sleeper LA, Webber SA, Pahl E, et al. Ventricular remodeling and survival are more favorable for myocarditis than for idiopathic dilated cardiomyopathy in childhood: an outcomes study from the Pediatric Cardiomyopathy Registry. Circ Heart Fail. (2010) 3:68997. doi: 10.1161/CIRCHEARTFAILURE.109.902833

2. Ghelani SJ, Spaeder MC, Pastor W, Spurney CF, Klugman D. Demographics, trends, and outcomes in pediatric acute myocarditis in the United States, 2006-2011. Circ Cardiovasc Qual Outcomes. (2012) 5:622-27. doi: 10.1161/CIRCOUTCOMES.112.9 65749

3. Duncan BW, Bohn DJ, Atz AM, French JW, Laussen PC, Wessel DL. Mechanical circulatory support for the treatment of children with acute fulminant myocarditis. J Thorac Cardiovasc Surg. (2001) 122:4408. doi: $10.1067 / \mathrm{mtc} .2001 .115243$

4. Rajagopal SK, Almond CS, Laussen PC, Rycus PT, Wypij D, Thiagarajan RR. Extracorporeal membrane oxygenation for the support of infants, children, and young adults with acute myocarditis: a review of the Extracorporeal Life Support Organization registry. Crit Care Med. (2010) 38:382-7. doi: 10.1097/CCM.0b013e3181bc8293
PLT count and serum protein levels than survivors. Arrhythmia was an indication for ECMO therapy.

\section{DATA AVAILABILITY STATEMENT}

The raw data supporting the conclusions of this article will be made available by the authors, without undue reservation.

\section{ETHICS STATEMENT}

The studies involving human participants were reviewed and approved by the Ethics Council of Vietnam National Children's Hospital (approval number: 331-BVNTW-VNVSKTE). Written informed consent to participate in this study was provided by the participants' legal guardian/next of kin.

\section{AUTHOR CONTRIBUTIONS}

TT, TX, PP, DH, and TD contributed to the conception and design of the study. TT, TX, and NVT collected the clinical information. TX wrote the first draft of the manuscript. TT, TX, and PP wrote sections of the manuscript. All authors have revised, read, and approved the final version of the manuscript.

\section{FUNDING}

This work was supported, in part, by Grant-in-Aid from the Vietnam National University-Hanoi, Vietnam (QGSP.21.02 to TT).

\section{ACKNOWLEDGMENTS}

We would like to thank Vietnam National University-Hanoi, Vietnam, and all the staff in the PICU of Vietnam National Children's Hospital.
5. Wu HP, Lin MJ, Yang WC, Wu KH, Chen CY. Predictors of extracorporeal membrane oxygenation support for children with acute myocarditis. Biomed Res Int. (2017) 2017:2510695. doi: 10.1155/2017/2510695

6. Wilmot I, Morales DLS, Price JF, Rossano JW, Kim JJ, Decker JA, et al. Effectiveness of mechanical circulatory support in children with acute fulminant and persistent myocarditis. J Card Fail. (2011) 17:48794. doi: 10.1016/j.cardfail.2011.02.008

7. Sagar S, Liu PP, Cooper LT Jr. Myocarditis. Lancet. (2012) 379:73847. doi: 10.1016/S0140-6736(11)60648-X

8. Extracorporeal Life Support Organization. ECLS Guidelines 2018, Guidelines for Pediatric Cardiac Failure. Available online at: https://www.elso.org/ Portals/0/IGD/Archive/FileManager/ELSO_Reformatted_2018.02.23.pdf (accessed September 16, 2020).

9. Mcintosh AM, Tong S, Deakyne SJ, Davidson JA, Scott HF. Validation of the vasoactive-inotropic score in pediatric sepsis. Pediatr Crit Care Med. (2017) 18:750-7. doi: 10.1097/PCC.0000000000001191

10. Lee EY, Lee HL, Kim HT, Lee HD, Park JA. Clinical features and short-term outcomes of pediatric acute fulminant myocarditis in a single center. Korean J Pediatr. (2014) 57:489-95. doi: 10.3345/kjp.2014.57.11.489

11. Ohki S, Hosokawa K, Tomioka S, Matsuoka M, Fushimi K, Matsuda S, et al. Pediatric fulminant myocarditis in Japan: a retrospective nationwide database 
study of hospital volume, management practices, and mortality. Pediatric Crit Care Med. (2021) 22:e391-401. doi: 10.1097/PCC.0000000000002692

12. Chang YJ, Chao HC, Hsia SH, Yan DC. Myocarditis presenting as gastritis in children. Pediatr Emerg Care. (2006) 22:43940. doi: 10.1097/01.pec.0000221346.64991.e7

13. Saji T, Matsuura H, Hasegawa K, Nishikawa T, Yamamoto E, Ohki H, et al. Comparison of the clinical presentation, treatment, and outcome of fulminant and acute myocarditis in children. Circ J. (2012) 76:12228. doi: 10.1253/circj.CJ-11-1032

14. Choudhury TA, Ofori-Amanfo G, Choi J, Eisenberg RE, Rycus P, Medar SS, et al. Left heart decompression on veno-arterial extracorporeal membrane oxygenation in children with dilated cardiomyopathy and myocarditis: an extracorporeal life support organization registry review. Pediatr Crit Care Med. (2021). doi: 10.1097/PCC.0000000000002775 (accessed Oct 18, 2021).

15. Lin YJ, Liu HY, Kuo HC, Huang CF, Hsu MH, Cheng MC, et al. Left ventricle decompression strategies in pediatric peripheral extracorporeal membrane oxygenation. Acta Cardiol Sin. (2019) 35:335-41. doi: 10.6515/ACS.201905 35(3).20181125A

16. Pinamonti B, Alberti E, Cigalotto A, Dreas L, Salvi A, Silvestri F, et al. Echocardiographic findings in myocarditis. Am J Cardiol. (1988) 62:28591. doi: 10.1016/0002-9149(88)90226-3

17. Lee EP, Chu SC, Huang WY, Hsia SH, Chan OW, Lin CY, et al. Factors associated with in-hospital mortality of children with acute fulminant myocarditis on extracorporeal membrane oxygenation. Front Pediatr. (2020) 8:488. doi: $10.3389 /$ fped.2020.00488

18. Angelini A, Calzolari V, Calabrese F, Boffa GM, Maddalena F, Chioin $\mathrm{R}$, et al. Myocarditis mimicking acute myocardial infarction: role of endomyocardial biopsy in the differential diagnosis. Heart. (2000) 84:24550. doi: 10.1136/heart.84.3.245

19. Kazmi SO, Sivakumar S, Karakitsos D, Alharthy A, Lazaridis C. Cerebral pathophysiology in extracorporeal membrane oxygenation: pitfalls in daily clinical management. Crit Care Res Pract. (2018) 2018:3237810. doi: 10.1155/2018/3237810

20. Robinson J, Hartling L, Vandermeer B, Sebastianski M, Klassen TP. Intravenous immunoglobulin for presumed viral myocarditis in children and adults. Cochrane Database Syst Rev. (2020) 8:CD004370. doi: 10.1002/14651858.CD004370.pub4

21. Yen CY, Hung MC, Wong YC, Chang CY, Lai CC, Wu KG. Role of intravenous immunoglobulin therapy in the survival rate of pediatric patients with acute myocarditis: a systematic review and meta-analysis. Sci Rep. (2019) 9:10459. doi: 10.1038/s41598-019-46888-0

22. Schultheiss HP, Kühl U, Cooper LT. The management of myocarditis. Eur Heart J. (2011) 32:2616-25. doi: 10.1093/eurheartj/ehr165

23. Cooper LT Jr, Hare JM, Tazelaar HD, Edwards WD, Starling RC, Deng MC, et al. Giant cell myocarditis treatment trial investigators. usefulness of immunosuppression for giant cell myocarditis. Am J Cardiol. (2008) 102:1535-9. doi: 10.1016/j.amjcard.2008. 07.041

24. Lampejo T, Durkin SM, Bhatt N, Guttmann O. Acute myocarditis: aetiology, diagnosis and management. Clin Med. (2021) 21:e50510. doi: 10.7861/clinmed.2021-0121

25. Turgeon PY, Massot M, Beaupré F, Belzile D, Beaudoin J, Bernier M, et al. Effect of acute immunosuppression on left ventricular recovery and mortality in fulminant viral myocarditis: a case series and review of literature. CJC Open. (2020) 3:292-302. doi: 10.1016/j.cjco.2020.10.017

26. Huang $\mathrm{X}$, Sun $\mathrm{Y}$, Su G, Li Y, Shuai $\mathrm{X}$. Intravenous immunoglobulin therapy for acute myocarditis in children and adults. Int Heart J. (2019) 60:359-65. doi: 10.1536/ihj. 18-299

Conflict of Interest: The authors declare that the research was conducted in the absence of any commercial or financial relationships that could be construed as a potential conflict of interest.

Publisher's Note: All claims expressed in this article are solely those of the authors and do not necessarily represent those of their affiliated organizations, or those of the publisher, the editors and the reviewers. Any product that may be evaluated in this article, or claim that may be made by its manufacturer, is not guaranteed or endorsed by the publisher.

Copyright (๑ 2021 Tuan, Xoay, Phuc, Hung, Dung, Truong, Thuan and Dien. This is an open-access article distributed under the terms of the Creative Commons Attribution License (CC BY). The use, distribution or reproduction in other forums is permitted, provided the original author(s) and the copyright owner(s) are credited and that the original publication in this journal is cited, in accordance with accepted academic practice. No use, distribution or reproduction is permitted which does not comply with these terms. 